\title{
Women Researchers in the Brazilian Music Scene
}

\author{
Dr. Cristina Rolim Wolffenbüttel \\ Postgraduate Program Studies in Education (PPGED) \\ State University of Rio Grande do Sul, Brazil \\ Camila de Luna Paiva \\ State University of Rio Grande do Sul, Brazil
}

\begin{abstract}
The interest for the female universe, their thoughts, and contributions has grown over the years. Research in several areas of knowledge has revealed the relevance of this contribution, at different times, including moments when women were not possible to make many appearances. In this sense, it is understood that, also, in the field of Music, the female contribution has been quite important, even though historiography has not yet presented many materials to substantiate this statement. In view of these assumptions, some questions arise: What have been the contributions of women in the making Brazilian music history? And, considering the importance of the female presence in Brazilian research, which women have been researching music and musical education over the years? Considering these issues, this research aimed to investigate the contribution of women in the making Brazilian music history, considering them as researchers. In order to conduct this research the methodology was structured in a qualitative approach, using documentary research and bibliographic research as methods, and also used document collection and Internet research as techniques for data collection. Data analysis was carried out through content analysis with theoretical references from sociology (Bourdieu, 2002), historical studies (Duby, 2009), and music education (Kraemer, 2000; Abeles; Hoffer; Klotner, 1984). It is understood that this research is relevant because by collecting and making the musical production of women public, whether as composers, interpreters or researchers, these data can integrate planning in music education. Therefore, it is intended to contribute to the creation of a culture of insertion for female production in music education, encouraging girls and women to launch themselves into the musical world as producers, in addition to reproducing the works produced by men throughout history.
\end{abstract}

Keywords: Education; Music Education; Music history; Women; Gender Studies.

\section{Introduction}

The development of music is often confused with the trajectory of music education throughout human history. For a long time, music has had a strong presence in human life in various forms and with different uses and functions (Merriam, 1964). Thus, one can also analyze music education, if understanding it as a field of studies that refers to the appropriation and transmission of music, in view of the relationship that is established between people (Kraemer, 2000). The practices that are established in music education, named music pedagogy, by Kraemer (2000), can occur in different places and can be presented under different functions and dimensions. In this way, uses and functions, from the anthropological point of view of music, dimensions and functions, in the perspective of music education, can support some reflections in both fields of study.

Merriam (1964) intended to provide an opportunity to understand the anthropological aspects of music explaining the relationship that occurs between society and music, naming it ethnomusicology. The researcher proposed that the objectives of the area cannot be achieved considering music as an object separate from the humans that compose it. There is, therefore, an intrinsic connection between music and the ways in which people act. From this perspective, Merriam (1964) has deeply studied the uses and functions of music and explained that they are very important for the study of human behavior. As for the uses of music, the author maintains that it can be used in a given society, in a way, being expressed directly as part of the popular evaluation. When dealing with the uses of music, the researcher refers to the ways in which it is used in human society, for habitual practice or customary exercise, either as something in itself or in conjunction with other activities. Thus, Merriam (1964) listed ten uses and functions of music, including emotional expression, aesthetic pleasure, entertainment, communication, symbolic representation, physical response, enforcing social norms, validating social institutions and religious rituals, contributing to continuity and stability of culture, contribution to the integration of society.

The analysis of this Merriam proposition allows (one) to relate it to the functions that, many times over the centuries, have been related or even destined to women. Here, they are about "caregiver" practices, whose presence of music and, in particular, the act of nurturing, has been related to women. 
In this sense, it is possible to mention the practice of lullabies, circle dance songs, and so many other songs passed from generation to generation by women (Wolffenbüttel, 1995, 1991). It is not claimed, however, that only women have practiced lullaby or other songs, as there are many examples of songs that are also sung by men. However, in particular, many lullabies and circle games had mothers and female caregivers, in general, as their great propagators. In this sense, when reflecting on musical practices, there seems to be a relationship between the uses and functions of certain songs and their destination, or even the direction of actions more directly related to women. In this sense, in view of the presence of women in the historicity of music development, and a kind of more direct relationship with musical expressions with more specific uses and functions, The Ways In which their performance has been reported in the history of music over the centuries, and of music education itself, based on the thinking of Kraemer (2000), could be analyzed from its dimensions and functions, relating to the issues based on cultural transmission and the historicalsociocultural situation. According to the author "Ideas about an aesthetic practice geared towards socially active education and training and through modes of sensitive and emotional knowledge need a qualified appreciation, a responsible and reasoned aesthetic pedagogical theory, since the processes of musical appropriation and transmission of individuals in a historical-sociocultural situation are carried out in the context of their respective musician-cultural daily life, and need interpretation in meaningful relationships to enable orientations and offer perspectives" (Kraemer, 2000, p. 66).

Taking into account the importance of the existence of moments of musical appreciation in music teaching, for example, which include, in addition to different artistic productions, gender diversity, with regard to the authorship of the works to be appreciated, it is understood that the approaches and materials used today, regarding the female presence in musical development and Brazilian musical education, are still scarce and, in a way, reduce the participation of women as composers and musicians in general. There are few known musical materials available for pedagogical-musical use that focus on the production of women in the Brazilian music scene. So, with a small number of existing and available materials, how can we provide music education that can, in the context of the daily music-cultural life of students, of any age, establish meaning as to the importance and contribution of the female presence in Brazilian music production? It is understood, as Kramer (2000, p. 66) points out, that music education should "make available not only knowledge about facts and contexts, but also principles of explanation, help for decision and guidance, for clarification, for influence and optimization of music-educational practice". Thus, it is the role of music education to define "along with the acquisition of knowledge: understand and interpret, describe and clarify, raise awareness and transform" (Kraemer, 2000, p. 66). By getting to know the musical production of women throughout the history of Brazilian music, it is possible to value this musical work and, also, encourage girls and women, in general, to put themselves as creators too, and not only reproducers of someone else's work.

In view of these assumptions and, based on Merriam (1964) and Kraemer (2000), the question is: What have been the contributions of women in the making Brazilian music history? And, considering the importance of the female presence in Brazilian research, which women have researched about music and music education over the years? Considering these issues, the present research aimed to investigate the contribution of women in the construction of the history of music in Brazil, considering them as researchers.

\section{Methodology}

The methodology used in this research was based on a qualitative approach, documentary and bibliographic research as methods, document collection and internet research as techniques for data collection, and content analysis as the technique for analyzing the data collected.

\subsection{Qualitative Approach}

According to Denzin and Lincoln (2006), qualitative research can present itself with different meanings, according to the existing complex historical field, as well as the diversity of each context. In this perspective and, according to the authors, qualitative research is understood as "a situated activity that locates the observer in the world. It consists of a set of material and interpretive practices that give visibility to the world. These practices transform the world into a series of representations, including field notes, interviews, conversations, photographs, recordings, and reminders" (Denzin \& Lincoln, 2006, p. 17).

Denzin and Lincoln (2006) highlight that qualitative research involves a naturalistic and interpretive approach to the world. In this sense, and according to the authors, investigations in this perspective study the objects of their research in the scenarios in which the facts occur, in order to understand or interpret the phenomena in terms of the meanings given to them by the participants in the investigations (Denzin \& Lincoln, 2006). 
In addition, the authors clarify that the "qualitative research involves the study of the use and collection of a variety of empirical materials - case study; personal experience; insight; life's history; interview; artifacts; cultural texts and productions; observational, historical, interactive and visual texts - which describe routine and problematic moments and meanings in the lives of individuals. Therefore, researchers in this field use a wide variety of interconnected interpretive practices, in hope that they will always be able to better understand the subject at their reach" (Denzin \& Lincoln, 2006, p. 17).

Bogdan and Biklen (1994) argue that qualitative investigations have five characteristics, with the possibility that, in some studies, they may be presented to a greater or lesser degree. For the authors, it is not a matter of determining whether the investigation is qualitative or not in its entirety, but of analyzing how qualitative the study is, in view of how often the characteristics inherent to the type of study appear.

According to the authors, the characteristics of this type of research have as a direct result of the data the natural environment, the descriptivity, the emphasis on the process instead of the product, the inductive form of data analysis, and the special attention that is devoted to the meaning. They also argue that the "process of conducting qualitative investigations reflects a kind of dialogue between researchers and their respective subjects, since they are not approached by them in a neutral way" (Bogdan \& Biklen, 1994, p. 51). The present investigation used the qualitative approach because it is not intended to quantify the data obtained, but to analyze them in their particularity, with a view to investigating the contribution of women in the making of the history of music in Brazil, considering them as researchers.

\subsection{Methods: Documentary Research and Bibliographic Research}

Gil (2010) argues that documentary research has similarities with bibliographic research. In this way, it is developed from material already prepared, "consisting mainly of books and articles" (Gil, 2010, p. 50). Bibliographic research has also been described as the initial stage of all scientific work, with the objective of gathering the information and data that will serve as a basis for the construction of the investigation, based on a given theme. In this investigation, bibliographic research was used as one of the research methods, in addition to documentary research. According to Oliveira (2007), the difference between bibliographic and documentary research resides in the sources that each uses. According to the author, documentary research "is characterized by the search for information in documents that have not received any scientific treatment, such as reports, newspaper reports, magazines, letters, films, recordings, photographs, among other dissemination materials" (Oliveira, 2007, p. 69). It is the type of research developed from the use of documents, whether current or old, considered authentic (Pádua, 1997).

Document is a term that comes from the Latin Documentum, derived from docere, which means to teach. Subsequently, the term assumed a connotation of evidence, being used in the legislative vocabulary (Le Goff, 1996).

Lima and Mioto (2007) explain that bibliographic research is often presented as a literature review. For the authors, this occurs because there is no adequate understanding of what literature review is. In this sense, Lima and Mioto (2007, p. 38) explain that "literature review is only a prerequisite for carrying out any and all research, whereas bibliographic research implies an ordered set of search procedures for solutions, attentive to the object of study, and that, therefore, cannot be random". In this way, the authors understand bibliographic research "as an important methodological procedure in the production of scientific knowledge capable of generating, especially in little-explored themes, the postulation of hypotheses or interpretations that will serve as a starting point for other research" (Lima \& Mioto, 2007, p. 44). In the perspective of bibliographic research, virtually several scientific texts and articles produced by women were sought in order to achieve the objective of investigating the contribution of women in the making Brazilian music history, considering themselves as researchers.

Regarding the use of documents in research, another method used in this research, Sá-Silva, Almeida, and Guindani (2009) argue that "it must be appreciated and valued. The wealth of information that we can extract and retrieve from them justifies its use in various areas of Human and Social Sciences because it makes it possible to broaden the understanding of objects whose understanding needs historical and socio-cultural contextualization" (Sá-Silva \& Almeida \& Guindani, 2009, p. 2).

In addition, Cellard (2008) explains that "the written document is an extremely precious source for every researcher in the social sciences. It is, of course, irreplaceable in any reconstruction referring to a relatively distant past, as it is not uncommon for it to represent almost all traces of human activity at certain times. Furthermore, very often, it remains the only testimony of particular activities that have occurred in the recent past" (Cellard, 2008, p. 295). 
For Bravo (1991), all sorts of productions by people that show themselves as evidence of their activities and that can reveal their ideas, opinions, ways of acting, and living are considered documents. Therefore, written, numerical, and statistical texts, reproductions of sounds and images can be considered as documents, among others (Bravo, 1991).

Gil (2010) explains that the first step in documentary research lies in the exploration of documentary sources, which are numerous, including documents that have not received analytical treatment - such as official documents, newspaper reports, letters, contracts, diaries, films, photographs, recordings, among other types of documents. There are also, according to Gil (2010), documents that, in some way, have already been analyzed, such as research reports, company reports, statistical tables, etc. Documentary research has been used extensively in historical research in the social sciences, with a view to describing and comparing social facts, with a view to establishing characteristics and trends (Pádua, 1997). For the reasons aforementioned and, considering that it was intended to collect musical documents produced by women, whether they are musical scores, phonographic records of recordings of copyrighted songs or other authorship, in addition to photographs and various other materials that would allow to reach the objective of this investigation, the choice of documentary research was adequate.

In this sense, the bibliographic and documentary research allowed to reveal the contribution of women in the construction of the history of music in Brazil, considering themselves as researchers.

\subsection{Techniques for Data Collection: Document Collection and Internet Research}

For data collection in this investigation, document collection and Internet research were used. Regarding the collection of documents, Silva, Damaceno, Martins and Sobral $(2009$, p. 4,558) explain that this presents itself as an important phase "of documentary research, demanding from the researcher some care and technical procedures about approaching the place where he or she intends to perform the 'mining' of sources that seem relevant to their investigation". For the authors, it is important that the approximation to the documents is formalized, so that it is possible to achieve the research objectives. In the same way, it is important that the procedures are followed, as it is crucial to have access to the collections and research sources.

The research spaces and types of information are diverse, depending on the nature of the research being undertaken. For this, it is important that the researcher knows the types of materials he should look for in his collection. In this regard, Silva, Damaceno, Martins, and Sobral (2009, p. 4.558) explain that "All of this knowledge is necessary for those who intend to carry out documentary research, as well as a balanced management of the time available to carry out the research. By carefully collecting documents, the researcher begins to better manage the time and relevance of the material collected".

In this investigation, several documents and materials produced by women related to the object of study were collected, including musical scores, phonographic and photographic records of presentations by women, as well as written productions about music and music education. In this way, the collection of documents played a major role in obtaining the data necessary to achieve the objectives. In addition to the collection of documents, research via the Internet also allowed the collection of data available online. In this regard, the specialized literature in the area of methodology has stood out in this type of data collection. Research carried out today has, for various reasons, resorted to the use of the Internet, not only as a means of data collection but also for analysis procedures and other uses that virtuality can offer. According to Freitas \& Muniz \& Mascarola (2004, p. 2), the "research process, along the lines traditionally practiced, is sometimes limited due to cost, time, geographical dispersion or work intensity. Such barriers can be exponentially resolved with the use of Internet technology". The choice of research via the Internet was corroborated by the fact that "not only are printing, posting, interviewing or data entry activities reduced, but it is also important to consider that the time between the moment information is provided and the dissemination of results considerably decrease" (Freitas \& Muniz \& Mascarola, 2004, p. 2). There are a number of tools in common use that have been used by most users in the virtual world in order to establish communication, interactivity, and information sharing. These spaces include chat rooms, forums or discussion groups, forms, e-mail, conferences, portals or virtual pages, among other spaces. According to Marcuschi (2002, p. 37), when it comes to virtual technologies, the "electronic address is one of the personal identifiers of individuals for all types of participation in electronic communication. However, in many cases, it does not appear, for example, in chat rooms. In the case of e-mails, they are always present as if they were the letter's envelope" (Marcuschi, 2002).

In addition, there is a standardization of electronic addresses, as occurs in postal addresses, which facilitates research. According to Marcuschi (2002, p. 37), "The same individual can have a multitude of email addresses depending on how many accounts or electronic mailboxes he has opened. With the current facilities and the multiplication of commercial providers that allow 'free electronic accounts', most people use more than one email address". 
The characteristics of Internet search allow a wide range of access possibilities to different data, which facilitates in terms of displacement, allowing greater coverage, at a lower cost. Therefore, the use of this type of research was justified, considering that several magazines focusing on Music and Music Education available online were investigated, such as the journals of the Brazilian Association of Musical Education - ABEM (Abem, 2020) and Opus (Opus, 2020), among many others that exist, having wide access through their websites.

In the case of procedures for data collection via the Internet, the taxonomy of research on search systems was used, such as the use of surfing, searching and browsing (Koch, 1996). For Koch, surfing is a non-systematic pursuit of links and browsing the systematic flipping of Web pages, aided by collections or reviews. The term searching is used by Koch (1996) to designate the search process with the help of databases built for this purpose. In this way, Koch (1996) explains that surfing would be equivalent to leafing through a book at random; browsing, searching the table of contents for a particular chapter, and searching would be for isolated facts and words using the index at the end of the book.

In this research, the three processes proposed by Koch (1996) were used, that is, the process of surfing on the Internet searching for links and browsing, leafing through websites related to magazine websites of the Brazilian Association of Musical Education and Opus, seeking the production of research by women in the Brazilian musical culture.

\subsection{Technique for Data Analysis: Content Analysis}

According to Yin (2005), a data analysis "consists of examining, categorizing, classifying in tables, testing or, otherwise, recombining quantitative or qualitative evidence to address the initial propositions of a study" (Yin, 2005, p. 137). The analysis of the data from this investigation was carried out through the use of content analysis. According to Moraes (1999), "content analysis is a research methodology used to describe and interpret the content of all types of documents and texts. This analysis, leading to systematic, qualitative or quantitative descriptions, helps to reinterpret the messages and achieve an understanding of their meanings at a level that goes beyond a common reading (Moraes, 1999, p. 9).

Olabuenaga and Ispizúa (1989) complement the understanding of content analysis by explaining that it is a technique for reading and interpreting the content of all types of documents that, when the necessary procedures are carried out, enable knowledge of aspects and phenomena of life socially inaccessible otherwise.

For the good progress of the research, the method proposed by Moraes (1999) was used, which well explains the procedures of a qualitative analysis with the use of content analysis. According to the author, there are five steps to be followed, namely, preparation of information, unitarization or transformation of content into units, categorization or classification of units into categories, description, and interpretation.

In the case of this research, whose objective was to investigate the contribution of women in the construction of the history of music in Brazil, considering themselves as researchers, the five stages occurred according to what was proposed by Moraes (1999).

\subsubsection{Preparation}

After collecting the data, which were obtained through the collection of documents and research via the Internet, they went through a preparation process. This process consisted of identifying samples of information to be analyzed. The procedure for this occurred after reading the material as a whole, deciding which ones were actually in accordance with the research objectives. The data included were, therefore, representative and pertinent to the research objective, covering the field to be investigated comprehensively, assigning codes to them, allowing the prompt return to information, when necessary. This procedure was important because, as Moraes (1999) explains, even if the material collected is already in possession, it needs to be prepared and transformed in order to be subjected to content analysis. After this procedure, unitarization started.

\subsubsection{Unitarization}

After preparing the data, they went through the process of unitarization. This occurred through a careful reading of all the material, in order to define the unit of analysis. According to Moraes (1999), the unit of analysis is the unitary element of content that is classified later. This categorization defined the elements of analysis, the information related to the contribution of women as musicians, composers and researchers in the construction of the history of music in Brazil, called the unit of analysis. For this definition the data were kept in full or, at times, were divided into smaller units, depending on the situation. After these procedures were carried out, all materials were reread, identifying the units of analysis, coding them. After these encodings, each unit of analysis was isolated, being rewritten and saved in virtual files, duly identified. 
In view of all these procedures, Moraes (1999) recommends care so that the information has a complete meaning in itself, without the aid of additional information. The justification for this is due to the fact that these units, in the later stages of the analysis, were treated outside the context of the original message, integrating themselves into new sets of information and, then, being understood and interpreted, maintaining the original meaning (Moraes, 1999). Finally, Moraes (1999) explains that, even though it is important that the definition of the units of analysis has meaning in itself, it is also a practice of content analysis to define, together with these units, another type of content unit, the context unit, which is a broader unit, and serves as a reference to it, setting contextual limits for interpreting it. Each context unit usually contains several units of record, helping to avoid losing context, exploring the meaning more fully. Once the units of analysis were identified and coded, they were categorized.

\subsubsection{Categorization}

The categorization consisted of grouping the data, considering the common part between them. They were classified by similarity or analogy, giving rise to thematic categories. As Olabuenaga and Ispizúa (1989) explain, the categorization process is a data reduction process. The categories represent the synthesis of communication highlighting, in this process, its most important aspects. It is the classification of the elements of a message, according to established criteria and facilitating the analysis of the information.

Moraes (1999) argues that data analysis occurs in a cyclical and circular way, and not sequential and linear. The data do not speak for themselves, but they need the meaning to be extracted from them, which is not achieved in a single effort. A periodic return to the data is indicated for the refinement of the categories. For a smooth running of the categorization task, it was important that the process met the characteristics of validity, completeness, homogeneity, exclusivity, and objectivity. The categories, in turn, needed to be valid, relevant, appropriate, exhaustive and homogeneous. The classification of any element of the content must be mutually exclusive. Finally, the classification must be consistent, objective, and reliable. All these characteristics of the categories prepared the description stage.

\subsubsection{Description}

According to Moraes (1999), the fourth stage of the content analysis process is the description. Once the categories are defined and the material of each is identified, the results are communicated. The description is the first moment of this communication. In a research with a qualitative approach, which was the case of the present investigation, a synthesis text was produced for each category, but it did not cover the interpretations, which occurred in the later stage. However, it could already contain more comprehensive descriptions, depending on the levels of categorization. In general, the organization of this description was determined by the category system built during the analysis. It was the moment to express the meanings captured and intuited in the analyzed messages (Moraes, 1999). It was intended, at this stage, to produce descriptions with some scope, seeking to focus on specific research questions about the contribution of women as researchers in the construction of the history of music in Brazil. Through these procedures of the description stage, it was intended, therefore, to reach the final stage, that isinterpretation.

\subsubsection{Interpretation}

Interpretation aims at understanding. The task of interpretation is to exercise interpretation in greater depth, including specialized literature and other research experiences, in addition to those experienced by the researcher. The interpretation stage was composed of two aspects. One of them constituted by the theoretical framework that includes studies of sociology (Bourdieu, 2002), historical studies (Duby, 2009) and concepts and foundations of Music Education, with Kraemer (2000) and Abeles, Hoffer and Klotman (1984). This aspect resulted from an exploration of the meanings expressed in the analysis categories, contrasted with this reasoning (Moraes, 1999). The other strand was built based on the data and the categories of the analysis. The theory emerged from information and categories. In this case, the construction of the theory itself was interpretation. Theorization, interpretation, and understanding constituted a circular movement in which, with each resumption of the cycle, an attempt was made to achieve greater depth in the analysis (Moraes, 1999). At the end of the five stages, preparation, unitarization, categorization, description, interpretation, it was intended to answer the objective of this research, that is, about the contribution of women as researchers in the construction of the history of music in Brazil.

\section{Theoretical Framework}

The theoretical framework of this research was made up of three perspectives. One of them included concepts from sociology, mainly based on Bourdieu (2002). Another reference was based on historical issues, in view of studies by Duby (2009). The third perspective used concepts of music education, mainly from Kraemer (2000) and the foundations of music education, referenced by the studies of Abeles, Hoffer and Klotner (1984). 


\subsection{Sociology: Women in Bourdieu's Studies}

Bourdieu (2002) deals with the presence of women in the economy of symbolic goods. According to the author, habitusis inseparable from the structures that "produce and reproduce" them (p. 27), whether in men or women. For the author, "The principle of inferiority and exclusion of women, which the mythical-ritual system ratifies and expands to the point of making it the principle of division of the entire universe, is nothing more than fundamental dissymmetry, that of the subject and the object, the agent and the instrument, established between men and women in the field of symbolic exchanges, of the relations of production and reproduction of symbolic capital, whose central device is the marriage market, which are at the base of the whole social order: women can only there to be seen as objects, or rather, as symbols whose meaning is constituted outside them and whose function is to contribute to the perpetuation or increase of the symbolic capital of men" (Bourdieu, 2002, p. 27).

Male hegemony, for Bourdieu (2002), is easily perceptible, including biological differences contributing factors in this understanding. However, based on this discourse of superiority, the notion of the inferiority of women was built, with biological bases, and naturalists described women as fragile females, who should maintain chastity, targeting marriage and procreation. In this way, women in an autonomous position, capable of creating, researching and carrying out so many other tasks, eminently masculine, have been unthinkable over the previous years. But, for sure, there were and there are many women who produced a lot. Considering the importance of unveiling the participation of women in the history of music in Brazil, it is understood that Bourdieu contributed to the reflections and conclusions of this research.

\subsection{Georges Duby and the Presence of Women in History}

Duby (2009), in his studies, focused attention on topics such as loneliness, family relationships, social behavior, marriage, and women. The importance of women, in particular, was given in the perspective of the continuity of existence, extending generations, through procreation. According to the author, "The feminine was positioned, certainly, under the entire domain of the masculine; however, because this woman was the wife, and was supposed to be the mother of the heirs - and, when she was unable, in the eleventh century, she was refused without hesitation - a portion of her "master's" power, as she said, was projected upon her: "lady" (from Latin, Domina), she also showed herself to be dominant, and to the same extent that, as a legitimate sexual partner and due to her genetic abilities, she contributed decisively to the extension of the house" (Duby, 2009, p. 77-78).

Another aspect that draws attention in historical reports is the fact that women are extremely watched and subjugated.The postulate that once held was that women were weaker and more prone to sin. Therefore, in this perspective, according to Duby (2009), "The head of the household's primary duty was to watch over, correct, kill, if necessary, his wife, his sisters, his daughters, widows, and daughters orphaned by his brothers, his cousins, and his vassals. Patriarchal power over femininity was reinforced because femininity represented danger. An attempt was made to conjure up this ambiguous danger by locking women in the most closed part of the domestic space, the bedroom the "ladies' room", which should not, in effect, be taken for a space of seduction, of fun, but of exile: they were closed there because men feared them" (Duby, 2009, p. 87-88).

When thinking about what women could do, in terms of daily and artistic activities, Duby (2009) explains that the tasks were specific. There was no possibility of idleness, which was even considered dangerous. So, there was a division "balanced between prayer and work, the work of the fabric. In the bedroom, washing, embroidering, and when poets of the 11th century make attempts to give the word to women, they compose songs 'to spin'. In fact, all the body ornaments and the ornate fabrics that decorated the room, the living room and the chapel came from female hands, that is, a considerable part of what we would call artistic, sacred and profane creation, but based on materials so perishable that only tiny fragments of it remain today. However, prayers and these works, performed as a team as they were, on the part of men, war and hunting, did not free them, persuaded from the structural perversity of female nature, from an obsessive, phantasmatic restlessness: what women do together, only among them, when they are locked in the room? Evidently, they do evil" (Duby, 2009, p. 89).

Therefore, considering a historical study in this investigation helped to understand how the construction of the contribution of women in Brazilian musical culture was and still is.

\subsection{Music Education: Perspectives from Kraemer, Abeles, Hoffer, and Klotman}

Kraemer (2000) deals with Music Education - calling it the pedagogy of Music - as an overlap between disciplines, discussing dimensions and functions of pedagogical-musical knowledge and highlighting the particularities of the area in relation to other disciplines. The author describes the places where the pedagogy of Music originates, as well as who is in charge of it. In his analysis, he clarifies that Music pedagogy deals with the relationship between people and music, dividing its object of study with the human sciences. 
It exemplifies these disciplines by focusing them on the philosophical, historical, psychological, sociological, musicological, pedagogical and other aspects that may have an important pedagogical-musical meaning. The author discusses the intertwining of Music pedagogy with other disciplines. It is noteworthy that a perspective of intertwining the area considers it as a result of the reciprocal link between the disciplines, creating a kind of web. This conception of interlacing proposes an enlarged dimension of the area, with more comprehensive and flexible limits. For Kraemer (2000), at the "center of musical reflections are the problems of appropriation and transmission of music" (p. 61). Pedagogy and pedagogy of Music do not constitute isolated disciplines and result in different groupings in the area. They are integration disciplines oriented towards action, according to the object of research.

For Kraemer (2000), the particularity of pedagogical-musical knowledge is "at the intersection of pedagogical ideas marked by human sciences, oriented by musical culture and aesthetic-musical ideas" (p. 66). In addition to the knowledge of facts and pedagogical-musical contexts, it is also necessary to make the principles of explanation of the music-educational practice available for the decisions, orientations, clarifications, influence, and optimization of these practices.

Finally, Kraemer (2000) proposes a structural model of Music pedagogy, which includes the analysis and the fields of application of the area, the aspects that compose it - musicological, pedagogical, among others - in addition to the functions of Music pedagogy - understand and interpret, describe and clarify, raise awareness, and transform the pedagogical-musical practice.

The thoughts of Abeles, Hoffer, and Klotman (1984) who, starting from a wide research on the history, philosophy, and functions of musical education in its social, psychological and pedagogical aspects, present themselves in their proposal that is directed to the teaching of Music in any environment. The authors explain the distinctive aspects of the main schools of thought, interpret the research findings and critically examine the assumptions underlying the various approaches to curriculum and teaching.

With regard to psychology, sociology, and social psychology for Music Education, the authors question how aspects such as social class, race, and other characteristics influence students' responses to different types of music. Likewise, they are concerned with understanding how classroom interactions affect the emergence of musical talent. The formation of attitudes, creativity, cognitive processing and behavioral techniques, curriculum development, cultural pluralism, music for disabled children, program evaluation, innovative approaches to assessment, responsibility, critical thinking, computer-based instruction, and music technology, among other important themes for Music Education, are also addressed by the authors (Abeles \& Hoffer \& Klotman, 1984).

In general, the authors present the philosophical, musical and aesthetic, sociological, socio-psychological and psychological foundations of Music Education.

Abeles, Hoffer, and Klotman (1984) list some reasons for music teachers to think about philosophical issues and how they relate to music teaching. One reason is that teachers have to make decisions as part of their job, and many of these decisions have philosophical implications.

The musical and aesthetic foundations of Music Education are supported in the perspective that living is more than a biological experience. Art and Music are manifestations of humanity's fundamental need for more than a mere existence, and they represent the desire for fulfillment and creation. This view is based on the interest that people have in the Arts through the ages (Abeles \& Hoffer \& Klotman, 1984).

Abeles, Hoffer, and Klotman (1984) present sociological concepts and their implications for music education. The ideas discussed by the authors include aspects such as nature/education, socialization, Music as a human behavior, Music functions, social stratification, age groups, pluralism, ethnocentrism, cultural patterns, mass taste, interrelation between the arts and the effects of technology in Music and Music Education.

In the discussion of the socio-psychological foundations of Music Education, Abeles, Hoffer, and Klotman (1984) deal with a series of concepts in the field of social psychology and its implications for music teachers. These ideas include self-image, conformity, expectation, feelings of competence, attitudes, competition/ cooperation, and creativity.

Finally, in the psychological foundations of Music Education, the authors organize topics that concern the factors that influence learning or the stages of the learning processes, such as child development and motivation. Sometimes, research results with the same theoretical currents may report to different psychological positions. In this sense, the authors deal with theoretical approaches that dominate the field of studies, including behaviorism and cognitivism. In addition to the approaches, Abeles, Hoffer, and Klotman (1984) deal with the child's development, cognitive process, motivation, factors related to the environment, and musical ability. 
The concepts and foundations of Music Education were important in the analysis of this research, because, considering the existence of women's productions in the Brazilian musical culture - this is what this research aimed to investigate it was necessary to reflect on how this production has been considered in pedagogical-musical planning, as well as in what quantity. In addition, the need to give more publicity to this production was pointed out in order to make education more democratic, breaking the aesthetic standards in force until then. For the inclusion of women's production in music education to be possible, it is necessary, first of all, that this production becomes known and available. It is understood, therefore, that this research contributed in this sense.

\section{Results and Data Analysis}

From the bibliographic research, it was noted that the investigation of the female presence has provided great contradictions and dualities, being strongly supported through male submission and domination in the face of women's own autonomy. To understand the importance and contribution of female composers in the history of music in Brazil is to recognize that, when talking about the history of music in Brazil, one also speaks of the history of women in Brazil. It is known that for many centuries the musical environment has been a privilege of men (Gomes \& Mello, 2019), and in the face of a constant path of ruptures and re-enactments, increasingly driven by counterculture movements, female composers in their various contexts, find ways to emancipate their voices through the Internet, acting in a representative way for so many other women and potentializing new resignifications and representations of the female figure in society.

With the great emergence of the field of music and genre in Brazil, it is observed that some areas still need further investigation, primarily, the contribution of musicians throughout the country. Based on the interviews conducted by Mayara Coelho, Marcos Silva and Marília Machado (2014) about gender differences in the musical bodies of São João del Rei, it is stated, that the biological characteristics are pointed out as determinants, limiting to the female body the "lightest" and most "delicate" instruments. According to Bourdieu (2002) the social world builds the body as a sexual reality and as a depository of sexualizing vision and division principles. Thus, the biological difference between the male body and the female body can be seen as a natural justification for the socially constructed division between genders. "The participation of most women is restricted to the choir and 'feminine' instruments such as violin and flute, delicate and easy to be carried. As for access to other functions within the musical bodies, very slowly, it has been ensured, mainly in the bands, where the participation of women occurs together with musicians, assuming both a character of renewal and a 'masculine' characteristic, given the strength of metals and percussion instruments. However, still, it cannot be said, quantitatively, that they are equal to male instrumentalists" (Coelho \& Silva \& Machado, 2014, p. 11).

Although some researchers have contributed to research on women musicians in Brazil, such as Vanda Freire and Angela Portella (2013) who investigated the performance of pianists in the halls and theaters of Rio de Janeiro, it is clear that research on women musicians has been forgotten throughout history (Souza, 2016). Since the division between genres also affects some musical instruments, potentially limiting stereotypes and binarisms, it is essential to investigate the life and contributions of musicians, in addition to the piano. There is a pluralism in society, which is made up of different groups, with different interests and lifestyles. Therefore, it is necessary that music teachers also consider all this pluralism and diversity (Abeles \& Hoffer \& Klotman, 1984), overcoming the imaginary boundaries between instruments for women and others for men.

Starting from the questioning about the importance of female presence in brazilian research, there was also a certain borderline between genders and the areas of musical education and music. This fact, product of the investigations undertaken in two important scientific journals of Music and Music Education, namely, the Brazilian Association of Musical Education Journal and the National Association of Research and Graduate Studies in Music Journal, called Opus Journal (Abem, 2020 \& Opus, 2020).

The Brazilian Association of Music Education began its activities in 1991, aiming to bring together professionals in the area and organize, systematize and consolidate critical thinking, research and performance in the area of Music Education. During the years of its existence, the Brazilian Association of Musical Education has promoted meetings, debates and sharing of experiences in all regions of the country. "The main objective of the Association is to promote music education in Brazil, contributing to the fact that music education is present systematically and with quality in the various Brazilian educational systems, covering, in a special way, basic education; for this reason, it has been attentive to the multiple forms of development of music teaching and learning in the country, which includes the training of music educators and the observation of public tender processes, as well as the hiring of professionals to teach music in the United States in different school levels" (Abem, 2020). 
Considering the relevance of the Brazilian Association of Musical Education Journal for the development of the area, in Brazil, a survey of all scientific production was carried out, which is from 1992 to 2019. Among the results, 445 published articles were found, distributed in 43 editions. When analyzing the authorship, it was possible to organize the data in three groups, including women, men, and groups of authors made up of women and men. With this configuration, 96 articles were found with male authors, 303 articles with women as authors, and 46 with men and women authors. The graph below shows the summary of these data.

Graph 1 - Publications Brazilian Association of Musical Education Journal (ABEM)

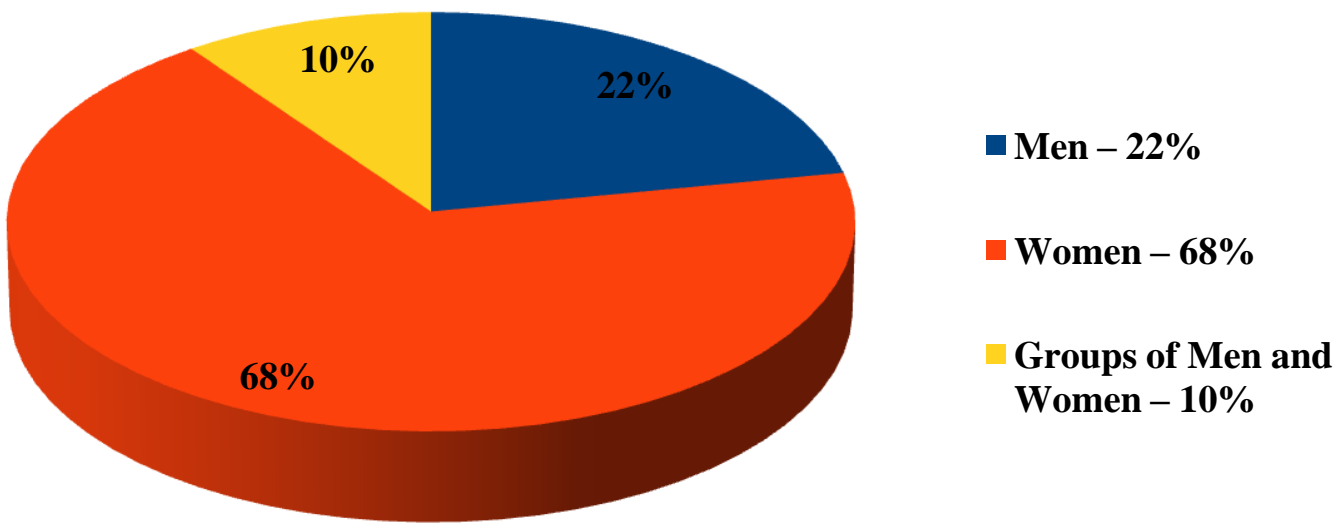

Source: the authors.

As visible in the graph, the number of female authors is quite significant, making up $68 \%$ of the total number of publications in the magazine, while male authors add up to $22 \%$. There is also the data on the number of articles written in partnership between male and female authors, with a total of $10 \%$.

It is also worth mentioning two aspects, regarding the data collected. One of them is that, initially, the number of female authors was even greater. From 1992, the year of the journals first publication, until 2004, the number of male authors ranged from one to four, at most. As of 2005, in volume 13 of the journal, the number of male authors increased to seven, and, in this edition, the number of male authors exceeded that of women. From the 2005 edition to the present, there was a gradual increase in the number of male authors. But, overall, the number of articles by women authors was still greater.

When analyzing the data collected in the Brazilian Association of Musical Education Journal, one can initially consider them quite interesting. And, at first, they are. But, if we think that this journal focuses on Music Education, it may be possible to think about other points of analysis. Musical Education presupposes the teaching and learning of Music, therefore, teaching. According to Bourdieu (2002), habitus are inseparable from the structures that produce and reproduce them. The task of teaching, often confused with the act of caring, has been assigned to women over the years. Obviously, they were given the teaching of "not so" important content, such as teaching the areas of Arts and, thus, Music, for example (Duby, 2009). Thus, the fact that women authors were found in a journal that discloses investigations around the teaching of Music, perhaps justified in terms of the habitus, to which Bourdieu refers.

In any case, despite the concepts with which it is important to deal, and that relate women as caregivers, it is important that there are women researchers in Music Education, and that their research is widely disseminated, as more and more of these names may appear among researchers, reflecting a very important aspect, and which are positive with regard to psychological issues. The more names of female researchers and authors, and as these names become well known, the more this will be reflected in the formation of habits and attitudes in the classroom (Abeles \& Hoffer \& Klotman, 1984). The second survey was carried out based on the Opus Journal, linked to the National Association of Research and Graduate Studies. Having been created in 1989, Opus Journal is "a four-monthly serial publication whose objective is to disseminate the plurality of knowledge in music, aspects considered of a practical, theoretical, historical, political, cultural and/or interdisciplinary nature - always encouraging the development of new methodological perspectives" 
(Opus, 2020). The journal's main focus is to compose an overview of the most representative results of music research in Brazil.

434 articles were found distributed in 42 editions, from 1989 to 2019. When analyzing the authorships, it was possible to organize the data in three groups, including women, men, and groups of authors made up of women and men. With this configuration, 232 articles were found with male authors, 124 articles with women as authors, and 78 with men and women authors. The graph below shows the summary of these data.

\section{Graph 2 - Publications Opus Journal}

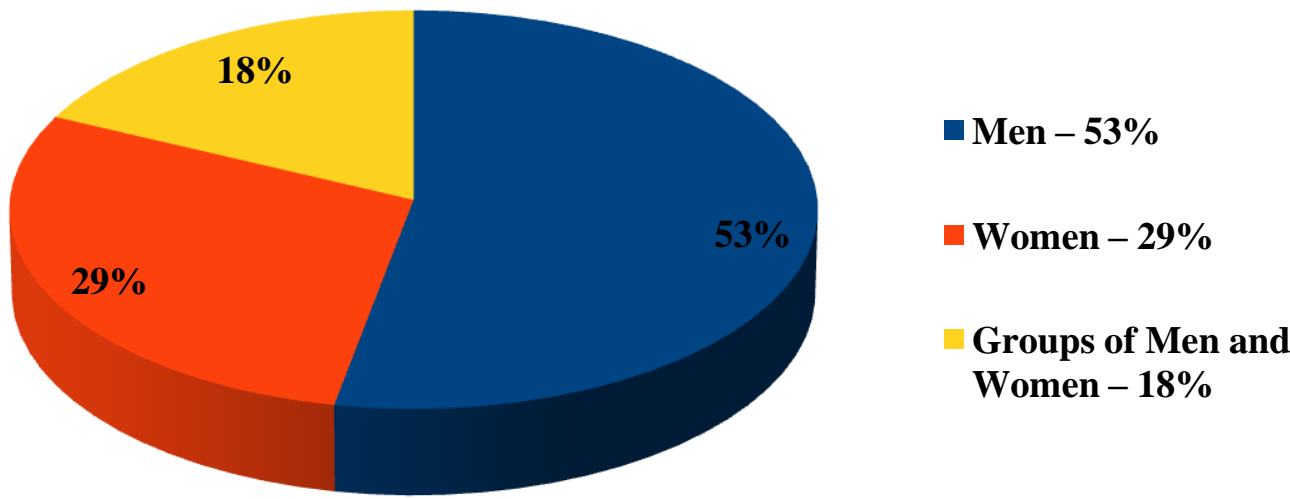

Source: the authors.

As visible in the graph, in the Opus Journal the opposite occurs when compared to the Brazilian Association of Musical Education Journal. The percentage of male authors is almost double the percentage of female authors. And, 53\% of the articles are authored by men, either with individual authors or with the partnership of other authors, also men. The percentage of authorship by women amounts to $29 \%$, revealing the male predominance. For authorship between both men and women, the percentage was $18 \%$.

The analysis around this data can be aided by the information that Opus Journal includes not only articles and research in Music Education, but also in areas such as Musicology, Ethnomusicology, Musical Analysis, Interpretive Practices, among other specificities of Music. Thus, it is understood that, historically, they are areas that most predominantly had men as protagonists.

If we consider what Kraemer (2000) advocates, this is an important issue to be questioned, to reflect on. It is a problem of "appropriation and transmission of music". If, on the one hand, when pedagogical-musical activities are carried out in class, music teachers do not include in their planning studies and listening activities with musical examples from female composers, performers and researchers, it will not be possible to awake children, girls, and young teenagers to the possibility of dedicating themselves to this area. Therefore, the results of this data collection demonstrate this.

In view of the aforementioned data, it is stated that women researchers are of great importance for the contribution of studies and methodologies that permeate Music Education. It can be seen from the Brazilian Association of Musical Education Journal that these researchers were responsible for providing, until the moment of this research, most of the articles available, which is already quite important. The scientific production produced by women and men was considered, in order to understand the particularity of each area presented and how this is also linked to gender social constructions. Throughout the 19th century, advertisements appeared in several periodicals in which women offer their services as music teachers. This activity was intensified over that period, gradually gaining social acceptance (Freire $\&$ Portella, 2013), since the female teacher refers to the affective, caring identity, that is, the maternal representation. Almeida (1998, p. 23) explains that for a long time "the teaching profession was practically the only one in which women could have the right to perform a decent job and achieve insertion in the public space, given that the other professional fields were forbidden". The possibility that existed previously was that of a teacher, since it was possible to combine motherhood and domestic work with this. 
According to Mateiro (2007, p. 179), this was a "starting point for social mobility, for the achievement of personal freedom and for the possibility of economic independence, especially for those women who did not marry. From that moment on, new paths emerged and economic, emancipatory, cultural, and social demands were conquered by women's movements". In this way, historically, it is observed that the area of Music Education remains contemplated by the feminine gender since female teachers reached acceptance and validation by the social environment. Thus, the data can be analyzed as a historical and symbolic echo of the spaces that were made socially available for the female gender. It is essential that these divisions are considered and overcome, and they are also related to the small number of teachers in composition programs at brazilian colleges, something similar to music degree courses with an habilitation to teach.

\section{Conclusion}

At the end of this research, which investigated the contribution of women in the construction of the history of music in Brazil, considering them as researchers, the relevance of its execution is understood. This is said, therefore, when collecting data from different sources - virtual and printed - it was understood that diverse and rich materials were unveiled, thus revealing the wealth of women's production in Brazil over the years and, perhaps, centuries, but little seen.

In the same way, it is understood that this research was relevant because, when collecting and making public the musical production of women, even if part of it, as researchers, these data can integrate class planning in music education. Thus, it will be possible to contribute to the culture of insertion of female production in music education, encouraging girls and women to launch themselves into the world of music as creators, in addition to reproducing the works produced by men, throughout history.

For centuries, starting from what constitutes the sexual and social division, women were isolated in private environments with their potential reduced to household chores. With the female counterculture movements, it is known that more and more public spaces have been places of struggle, rupture and expression also for women. From the history of music and research in music, I conclude that three moments and movements were essential for new discussions of female representation in these two areas.

The passage from the 19th to the 20th century is reiterated as a landmark for the insertion of women musicians in Brazilian halls and theaters. Transmuting its significance in not only the lady who welcomed guests, as the morality of female education proposed, but rather as autonomous from her own knowledge and potential. With composition, it is known that the end of the 60's was essential for a new narrative of Brazilian women composers, presenting in their lyrics a more feminist bias. This research is concluded by reiterating that research on music and gender, a field of study driven by women, is crucial to a less sexist and masculine musical education.

Investigating, making visible, sharing and legitimizing women's contributions to the history of music in Brazil means recognizing all the centuries of historical, symbolic, and social silence. This research, therefore, intended to analyze the appropriate data from sociology and historical studies, since, to investigate female participation in a given space is to question which spaces have not yet been occupied by women, or remain sulternized. Reflections such as these are urgent in the planning of music education and insertion in curricular menus, understanding that the academia itself acts for the maintenance of gender from, also the musical feminicide. Thus, it is stated that it is essential to recognize the studies of music and gender in Brazil as a scientific field and trigger for new paths, questions, and epistemologies.

Finally, it is understood the great contribution of female researchers in the field of musical education, acting strongly in teaching materials, as well as in scientific productions through methodologies and public policies. In addition, the product of many individual women's movements, music and gender studies are constantly expanding, recognizing here the need to talk about all women, absent from Eurocentric, racist, and cisgender aspects. It is believed that, thus, it will be possible to contribute more and more with the insertion of the female production of music education, encouraging girls and women to launch themselves into the world of music as composers, in addition to reproducing the works produced by men throughout history.

\section{Acknowledgements}

Eduardo Filipe Albrecht Lassig, Rio Grande do Sul Research Support Foundation (FAPERGS), National Council for Scientific and Technological Development (CNPq). 


\section{References}

Abeles, H. F.; Hoffer, C. R.; Klotman, R. H. (1984). Foundations of music education. New York: Schirmer.

Abem. (2020).Quem somos.http://abemeducacaomusical.com.br/abem.asp\#t1.

Almeida, J. S. de. (1998). Mulher e educação: a paixão pelo possível. São Paulo: Editora da UNESP.

Bogdan, R. C.; Biklen, S. K. (1994). Investigação qualitativa em educação: uma introdução à teoria e aos métodos. Porto: Porto Editora.

Bourdieu, P. (2002). A dominação masculina. Rio de Janeiro: Bertrand do Brasil.

Bravo, R. S. (1991). Técnicas de investigação social: Teoria e ejercicios. Madrid: Paraninfo.

Cellard, A. (2008). A análise documental. In: POUPART, J. et al. A pesquisa qualitativa: enfoques epistemológicos e metodológicos. Petrópolis, Vozes, 2008.

Coelho, M. P.; Silva M. V.; Machado, M. N. da M. (2014). Sempre tivemos mulheres nos cantos e nas cordas: Uma pesquisa sobre o lugar feminino nas corporações musicais. Rio de Janeiro: Fractal- Revista de Psicologia, v. 26, p. 107-122.

Denzin, N. K.; Lincoln, Y. (2006). Planejamento da pesquisa qualitativa: teorias e abordagens. Porto Alegre: ARTMED.

Duby, G. (Org.). (2009). História da vida privada: Da Europa feudal à Renascença. São Paulo: Companhia das Letras.

Freire, V. L. B.; Portella, A. C. H. (2013). Mulheres compositoras: da invisibilidade à projeção internacional. In: Nogueira, I. P.; Fonseca, S. C. (Org.). Estudos de gênero, corpo e música: abordagens metodológicas. ANPPON - Pesquisa e música no Brasil. v. 3, p. 279-302.

Freitas, H.; Janissek-Muniz, R.; Mascarola, J. (2004). Uso da Internet no processo de pesquisa e análise de dados. Associação Nacional de Empresas de Pesquisa (2004: São Paulo). [Anais...]. [São Paulo: ANEP. http://www.ufrgs.br/gianti/files/artigos/2004/2004_147_ANEP.pdf.

Gil, A. C. (2010). Métodos e técnicas de pesquisa social. São Paulo: Atlas

Gomes, R. C. S.; Mello, M. I. C. (2019). Relações de gênero e a música popular brasileira: um estudo sobre as bandas femininas. Florianópolis: DAPesquisa, v. 2, n. 4, p. 500-510, nov.

Koch, T. Internet search services. (1996). http://www.ub.uni-dortmund.de/Inetbib/programm.htm

Kraemer, R. (2000). Dimensões e funções do conhecimento pedagógico-musical. Em Pauta, Porto Alegre, v.11, n. 16/17, abr./nov., p.50-73.

Le Goff, J. (1996). História e memória. Campinas, São Paulo: Editora da UNICAMP.

Lima, T. C. S. de; Mioto, R. C. T. (2007). Procedimentos metodológicos na construção do conhecimento científico: a pesquisa bibliográfica. Rev. Katál. Florianópolis v. 10 n. esp. p. 37-45. http://www.scielo.br/pdf/rk/v10nspe/a0410spe

Marcuschi, L. A.(2018). Gêneros textuais emergentes no contexto da tecnologia digital.

https://pt.scribd.com/document/132876124/Marcuschi-Generos-Textuais-Emergentes-No\#download

Mateiro, T. (2007). Do tocar ao ensinar: o caminho da escolha. Opus, Goiânia, v. 13, n. 2, p. 175-196, dez.

Merriam, A. P. (1964). The anthropology of music. Evanston, Illinois: Northwestern University Press.

Moraes, R. (1999). Análise de conteúdo. Educação, Porto Alegre: Pontifícia Universidade Católica do Rio Grande do Sul, ano XXII, n.37, pp.7-31, março.

Olabuenaga, J. I. R.; Ispizua, M. A. (1989). La descodificacion de la vida cotidiana: metodos de investigacion cualitativa. Bilbao, Universidad de Deusto.

Oliveira, M. M. de. (2007). Como fazer pesquisa qualitativa. Petrópolis, Vozes.

Opus. (2020). Sobre a Opus.https://www.anppom.com.br/revista/index.php/opus/index.

Pádua, E. M. M. de. (1997). Metodologia da pesquisa: abordagem teórico-prática. Campinas: Papiros.

Sá-Silva, J. R.; Almeida, C. D. de; Guindani, J. F. (2009). Pesquisa documental: pistas teóricas e metodológicas. Revista Brasileira de História \& Ciências Sociais.Ano I - Número I - jul, p. 1-15. https://periodicos.furg.br/rbhcs/article/view/10351

Silva, L. R. C. da; Damaceno, A. D.; Martins, M. da C. R.; Sobral, K. M. (2009). Pesquisa documental: alternativa investigativa na formação docente. IX Congresso Nacional de Educação - EDUCERE. III Encontro Sul Brasileiro de Psicopedagogia. Anais. Porto Alegre. 26 a 29 de outubro. PUCRS.

Souza, A. da P. (2016). Musicologia e seus caminhos: um olhar sobre as pesquisas sobre mulheres musicistas no Século XIX. Belo Horizonte: XXVI Congresso da Associação Nacional de Pesquisa e Pós -Graduação em Música.

Wolffenbüttel, C. R. (1991). Acalantos. Porto Arte: Revista de Artes Visuais, v. 2, n. 3, abr. DOI: https://doi.org/10.22456/2179-8001.27411

Wolffenbüttel, C. R. (1995). Cantigas de ninar. Porto Alegre: Magister. 
Yin, R. K. (2015). Estudo de caso: planejamento e métodos. Porto Alegre: Bookman.

Graph 1

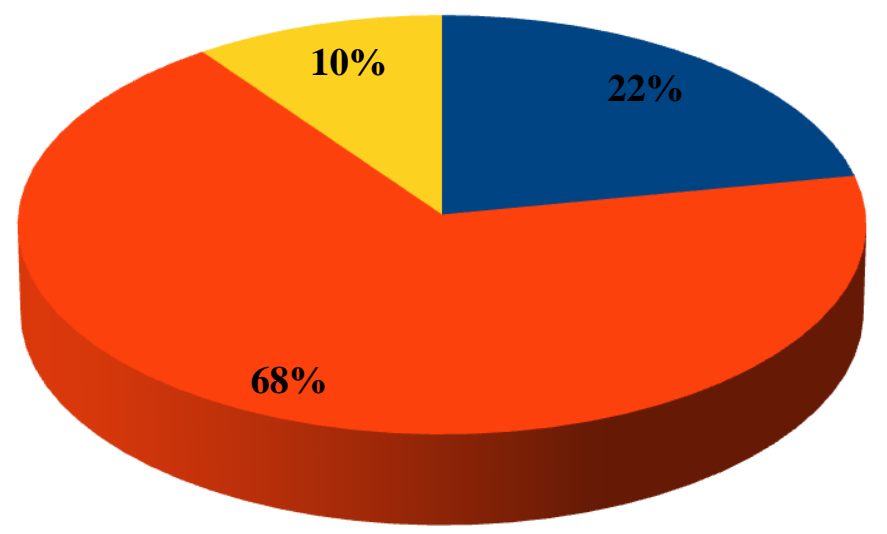

- Men $-22 \%$

Women $-68 \%$

Groups of Men and

Women $-10 \%$

Graph 2

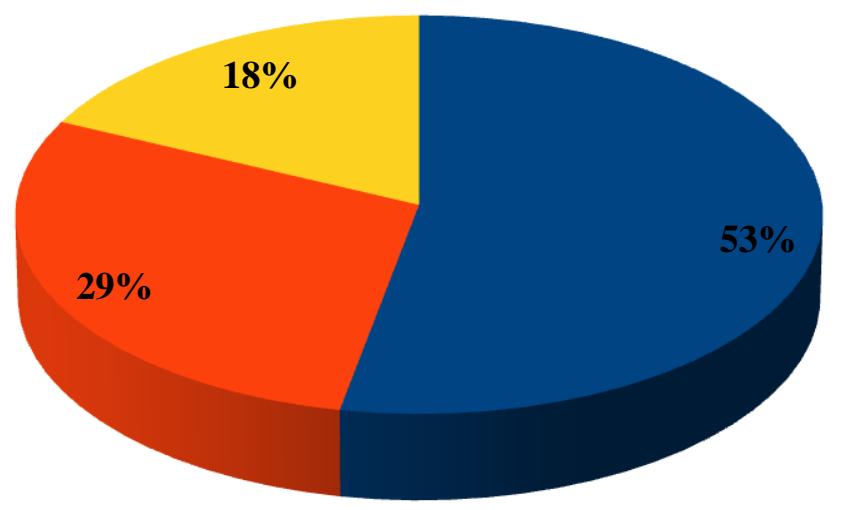

- Men $-\mathbf{5 3 \%}$

- Women - 29\%

Groups of Men and

Women $-18 \%$ 